\title{
Qualidade dos grãos de milho em função da umidade de colheita e da temperatura de secagem ${ }^{1}$
}

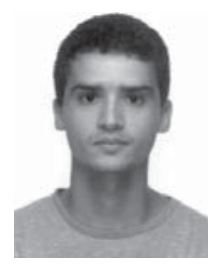

Wederson M. Alves², Lêda R. D'Antonino Faroni ${ }^{3}$, Daniel M. de Queiroz ${ }^{4}$, Paulo C. Corrêa ${ }^{5}$ \& João C. C. Galvão 6

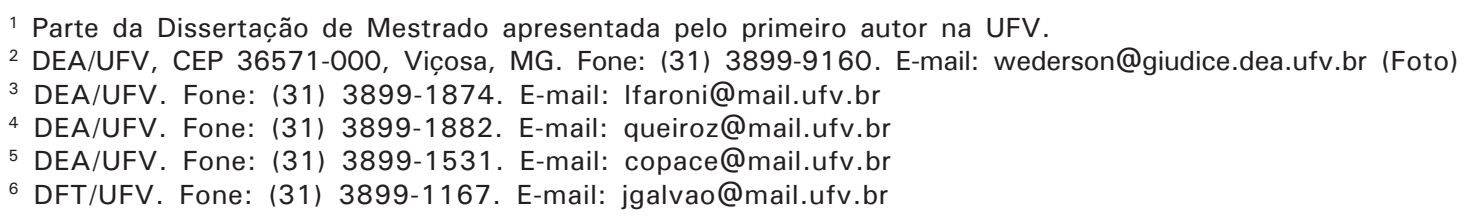

Protocolo $014-6 / 2 / 2001$

\begin{abstract}
Resumo: Com este trabalho, objetivou-se avaliar o efeito imediato e latente de quatro teores de umidade de colheita, associados a quatro níveis de temperatura do ar de secagem sobre a qualidade do milho, colhido com 25, 22, 16,5 e 15\% b.u. e secado nas temperaturas de 40,60, 80 e $100{ }^{\circ} \mathrm{C}$, até a umidade final de $13 \%$ b.u. Os grãos foram submetidos às análises de teor de impureza e matéria estranha, massa específica aparente, índice de danos, índice de trincas e susceptibilidade à quebra. De modo geral, pode-se inferir que os grãos colhidos com os teores de umidade de 15 e 16,5\% e secos nas temperaturas do ar de secagem de 40 e $60{ }^{\circ} \mathrm{C}$, foram os tratamentos que menos afetaram a qualidade do milho.
\end{abstract}

Palavras-chave: Zea mays L., armazenamento, danos mecânicos, perdas

\section{Quality of corn grains as a function of harvesting moisture content and drying air temperature}

\begin{abstract}
The objective of this work was to evaluate the immediate and latent effects of four harvesting moisture contents associated with four levels of drying-air temperature on the corn quality, harvested with 25, 22, 16.5 and $15 \%$ wb. moisture content and dried with air temperatures of $40,60,80$ and $100{ }^{\circ} \mathrm{C}$ until the final moisture content of $13 \% \mathrm{wb}$. The grains were submitted to analyses of impurity content and foreign materials, apparent specific mass, index of damages, index of creaking and breakage susceptibility. In general, it may be mentioned that the grains harvested with moisture contents of 15 and $16.5 \%$ and dried at air temperatures of 40 and $60{ }^{\circ} \mathrm{C}$ resulted in better corn quality.
\end{abstract}

Key words: Zea mays L., storage, mechanical damage, loss

\section{INTRODUÇÃO}

O milho é cultivado mundialmente por todos os povos e ocupa, dentre os cereais, o terceiro lugar em área plantada e em produção global (Fornasieri Filho, 1992).

O Brasil ocupa a terceira posição na produção mundial de milho, superado apenas pelos Estados Unidos e pela China Continental, responsáveis por 70\% da produção (Minas Gerais, 1995). Dos 83 milhões de toneladas de grãos produzidos na safra 99/00, a contribuição do milho foi cerca de $39 \%$ da produção (Brasil, 2000).

Apesar de toda a capacidade produtiva do Brasil, muito ainda tem que ser feito para melhor se atender à exigência dos mercados nacional e internacional quanto à qualidade dos grãos, preocupação primordial, fazendo com que as práticas adotadas da colheita ao armazenamento, sejam as mais adequadas.
A obtenção de grãos de alta qualidade depende de diversos fatores, como: características da espécie e da variedade, condições ambientais durante o seu desenvolvimento, época e procedimento de colheita, método de secagem e práticas de armazenagem (Brooker et al., 1992).

Diversos trabalhos mostram a preocupação em se determinar a melhor época de colheita dos grãos de milho, danificando-os o menos possível evitando, assim, perdas desnecessárias. Melendez et al. (1992) relataram que, a medida em que o teor de umidade dos grãos diminui, aumentam as perdas. Entretanto, outros autores, como Thompson \& Foster (1963), Araújo (1995) e Silva (1997) concluíram que o efeito dos danos mecânicos sobre a qualidade das sementes e dos grãos de milho foi mais prejudicial quando foram colhidos com maior teor de umidade. 
Apesar de todos esses estudos envolvendo a melhor época de colheita dos grãos de milho, normalmente a colheita é realizada com os grãos ainda muito úmidos, tornando necessário, portanto, fazer-se a secagem deste produto até o teor de umidade adequado, para que se tenha um armazenamento seguro.

A secagem artificial destaca-se por sua grande importância dentro do sistema de produção agrícola, ressaltando-se que, por meio dela, pode-se antecipar a colheita, armazenar o produto por longo tempo sem que haja deterioração do mesmo, manter a viabilidade de sementes e, também, permitir ao agricultor vender um produto de melhor qualidade (Henderson et al., 1997). Entretanto, este tipo de secagem constitui o estágio mais crítico na produção de produtos agrícolas, pois se for conduzida em condições não apropriadas, os danos serão irreversíveis, prejudicando a comercialização ou o processamento (Brooker et al., 1992).

A temperatura, a umidade relativa, a velocidade do ar de secagem, a taxa de secagem do produto, o teor de umidade inicial e final do produto, o sistema de secagem empregado e o tempo de residência do produto na câmara de secagem, são os principais parâmetros que podem estar associados à redução da qualidade dos grãos e sementes (Brooker et al., 1992). Neste sentido, diversos estudos têm sido feitos para se avaliar o efeito da temperatura do ar de secagem, associado a outros fatores, sobre a redução da qualidade fisiológica dos grãos.

Em estudos para avaliar o efeito da temperatura do ar de secagem e umidade inicial de colheita sobre a qualidade fisiológica e os danos mecânicos do milho, Franceschini (1997) observou que a suscetibilidade à quebra (SQ) aumenta com a temperatura do ar de secagem e Peplinski et al. (1994) verificaram que com o aumento da temperatura do ar de secagem, a percentagem de germinação era reduzida.

$\mathrm{O}$ armazenamento de grãos também faz parte do sistema pós-colheita. A importância da armazenagem bem conduzida reside no fato de que um armazenamento adequado e seguro dos produtos agropecuários evita perdas e preserva a qualidade. Assim como ocorre para a colheita, há um teor de umidade apropriado para o armazenamento de grãos, durante o qual o teor de umidade deve ser mantido em níveis que impeçam ou dificultem a proliferação de fungos e insetos. Os fatores de qualidade a serem preservados dependem do uso final dos grãos (Montross et al., 1999).

Segundo Bakker-Arkema (1994), para se avaliar a qualidade dos grãos, consideram-se diversas propriedades qualitativas, como teor de umidade, massa específica, percentual de grãos quebrados, teor de impureza e matéria estranha, danos causados pela secagem, susceptibilidade à quebra, qualidade de moagem, conteúdo de proteínas, valor como ração, viabilidade como semente, presença de insetos e fungos, e tipo de grão e ano de produção; entretanto, nem todas estas características qualitativas são consideradas, apesar de serem de grande importância para compradores internacionais mas, segundo Roskens (1995) há tendência mundial para se aprimorarem os padrões de classificação, acrescentando mais fatores de qualidade.

Devido às diversas operações (colheita, transporte, secagem e armazenamento) pelas quais passam os grãos, e aos fatores (físicos, químicos e biológicos) que atuam sobre eles, torna-se necessário estudar e planejar ações que reduzam os índices de perdas ao mínimo, para que se possa obter um produto de melhor qualidade e maior preço final. Por isso, o presente trabalho teve por objetivo avaliar o efeito imediato e latente de quatro teores de umidade na época da colheita, associados a quatro temperaturas do ar de secagem sobre a qualidade dos grãos de milho durante o armazenamento.

\section{MATERIAL E MÉTODOS}

Os grãos de milho (Zea mays L.) utilizados neste estudo, do híbrido duplo AG 1051, foram colhidos em campo experimental do Departamento de Fitotecnia e as análises realizadas no Laboratório de Pré-Processamento de Produtos Agrícolas do Departamento de Engenharia Agrícola, todos na Universidade Federal de Viçosa, MG.

\section{Colheita}

Os grãos foram colhidos com quatro teores de umidade ( 25 , $22,16,5$ e $15 \%$ b.u.) por meio de uma colhedora combinada "autopropelida", com plataforma de colheita para duas linhas.

$\mathrm{O}$ teor de umidade foi determinado pelo método-padrão de estufa, $105 \pm 3{ }^{\circ} \mathrm{C}$ durante $24 \mathrm{~h}$, com três repetições, conforme recomendações da regras para análise de sementes (Brasil, 1992).

\section{Secagem}

A secagem foi realizada em um secador experimental de camada delgada, com controle de temperatura (por meio de três resistências) e velocidade do ar de secagem (por meio da abertura e de fechamento do diafragma acoplado na entrada do ventilador). Os testes só eram iniciados quando as condições de velocidade e temperatura do ar de secagem eram constantes. Os grãos não foram limpos antes do processo de secagem; por outro lado, a velocidade do ar de secagem utilizada foi de cerca de $0,3 \mathrm{~m} \mathrm{~s}^{-1}$, medida por um anemômetro digital de lâminas rotativas.

As temperaturas do ar de secagem empregadas foram de $40,60,80$ e $100 \pm 1{ }^{\circ} \mathrm{C}$, medidas imediatamente abaixo da bandeja que continha os grãos de milho.

$\mathrm{O}$ processo de secagem era finalizado quando o teor de umidade do produto atingia aproximadamente $13 \%$ b.u., o que era conseguido por intermédio de pesagens periódicas da amostra, utilizando-se uma balança de $0,01 \mathrm{~g}$ de precisão.

\section{Armazenamento}

Depois da secagem, amostras de aproximadamente $5 \mathrm{~kg}$ de cada tratamento foram acondicionadas em recipientes metálicos de aproximadamente $18 \mathrm{~L}$ para o armazenamento; em seguida, os recipientes foram desinfestados por meio de uma fumigação com fosfeto de alumínio, durante um período de exposição de $120 \mathrm{~h}$ e cobertos com uma malha de algodão muito fina, de forma a possibilitar a respiração dos grãos e impedir a reinfestação por insetos provenientes do meio ambiente externo. Esses recipientes foram, então, armazenados em condições de laboratório, pelo período de $120 \mathrm{~d}$.

Para se avaliar a qualidade dos grãos durante o armazenamento coletou-se, no início e a cada $30 \mathrm{~d}$, uma amostra de $300 \mathrm{~g}$ em cada recipiente metálico, as quais foram submetidas às análises de impureza e matéria estranha, massa específica 
aparente, índice de danos, índice de trincas e susceptibilidade à quebra. Em razão de os grãos de milho terem sido secos em um secador de camada fixa e não terem sido movimentados durante o armazenamento, a análise de impureza e matéria estranha e a de massa específica aparente dos grãos foram realizadas somente no início do armazenamento.

Para o cálculo do teor de impureza e matéria estranha do milho, as amostras foram passadas em peneira de crivo circular de 4,76 mm de diâmetro e, depois, todo o material foi pesado, enquanto o percentual de impureza e matéria estranha foi expresso em relação à massa inicial da amostra. Por sua vez, a massa específica aparente foi determinada em uma balança de peso hectolítrico de $0,25 \mathrm{~L}$, utilizando-se os grãos que ficaram retidos na peneira de crivo circular de 4,76 mm de diâmetro e, para se avaliar os danos visíveis gerais causados pela colheita e secagem, determinou-se o índice de danos pela Eq. 1, proposta por Chowdhury \& Buchele (1976):

$$
\text { ID }=d_{1}+d_{2}+0,6 d_{3}+0,2 d_{4}+0,1 d_{5}
$$

em que:

ID - índice de danos, adimensional

$\mathrm{d}_{1} \quad$ - grãos quebrados e material fino, que passam por uma peneira de crivos circulares de 4,76 mm de diâmetro, \%

$\mathrm{d}_{2}$ - danos severos (faltando mais da metade do grão), \%

$\mathrm{d}_{3}$ - danos maiores (faltando metade ou menos da metade do grão e apresentando trincas no embrião), $\%$

$\mathrm{d}_{4}$ - danos pequenos (estragos superficiais), $\%$

$\mathrm{d}_{5}$ - grãos não-danificados, $\%$

Estas percentagens foram estimadas por inspeção visual, auxiliada por uma solução de iodo a $4 \%$, que torna escuro o endosperma exposto nas regiões quebradas, rachadas ou mesmo naquelas faltando pequenos pedaços do tegumento.

Para avaliação do índice de trincas dos grãos, utilizaram-se amostras de 100 g de grãos inteiros (aparentemente sadios) escolhidos aleatoriamente na amostra inicial. Eles foram avaliados individualmente por meio de um diafanoscópio, através de observação visual.

O índice de trincas foi determinado pela Eq. 2, proposta por Bakker-Arkema, (1994):

$$
\mathrm{IT}=\mathrm{T}_{1}+3 \mathrm{~T}_{2}+5 \mathrm{~T}_{3}
$$

em que:

IT - índice de trincas

$\mathrm{T}_{1}$ - percentagem de grãos sem trincas

$\mathrm{T}_{2}$ - percentagem de grãos com uma trinca

$\mathrm{T}_{3}$ - percentagem de grãos com duas ou mais trincas

A susceptibilidade à quebra, devido a colheita e secagem, foi estimada com o auxílio de um aparelho "Stein Breakage Tester", modelo CK. Para os testes, foram utilizadas amostras de $100 \mathrm{~g}$ de grãos limpos, e cada uma colocada em recipiente de aço de $9 \mathrm{~cm}$ de diâmetro que, a uma rotação de 1800 rotações min $^{-1}$, jogava os grãos contra a parede do recipiente durante 4 min; logo depois, a amostra foi passada em peneira de crivos circulares de 4,76 mm de diâmetro. Todo o material que passou pela peneira era pesado e o percentual de grãos quebrados foi expresso em relação à massa inicial da amostra.

\section{Análise estatística}

Os efeitos imediato e latente de quatro teores de umidade de colheita $(25,22,16,5$ e $15 \%$ b.u. $)$ associados a quatro temperaturas do ar de secagem $\left(40,60,80\right.$ e $\left.100^{\circ} \mathrm{C}\right)$ e a cinco períodos de armazenamento $(0,30,60,90$ e 120 d) em três repetições, foram avaliados em delineamento inteiramente casualizado, em esquema fatorial 4 × 4 × 5, mediante a análise de variância e, para os casos em que as interações foram significativas, fez-se a análise de regressão.

Para a escolha dos modelos levou-se em consideração, além do ajuste, a análise de resíduos, a significância dos $\beta$ 's e a melhor representação física do fenômeno em estudo devido a própria natureza de variabilidade dos parâmetros físicos, impurezas e matérias estranhas, índice de danos e susceptibilidade à quebra dos grãos.

\section{RESULTADOS E DISCUSSÃO}

\section{Teor de impureza e matéria estranha}

Na Figura 1 é representado o efeito da temperatura do ar de secagem e do teor de umidade de colheita sobre o teor de impureza e matéria estranha. Observa-se que, para os grãos colhidos com teor de umidade entre 16,5 e $22 \%$, o teor de impureza dos grãos foi maior que nas demais umidades de colheita, independentemente da temperatura do ar de secagem utilizada. Os menores valores do teor de impureza e matéria estranha foram obtidos para o teor de umidade de colheita de $15 \%$. Estes resultados estão de acordo com os encontrados por Silva (1997) que observou que o milho colhido com $20,5 \%$

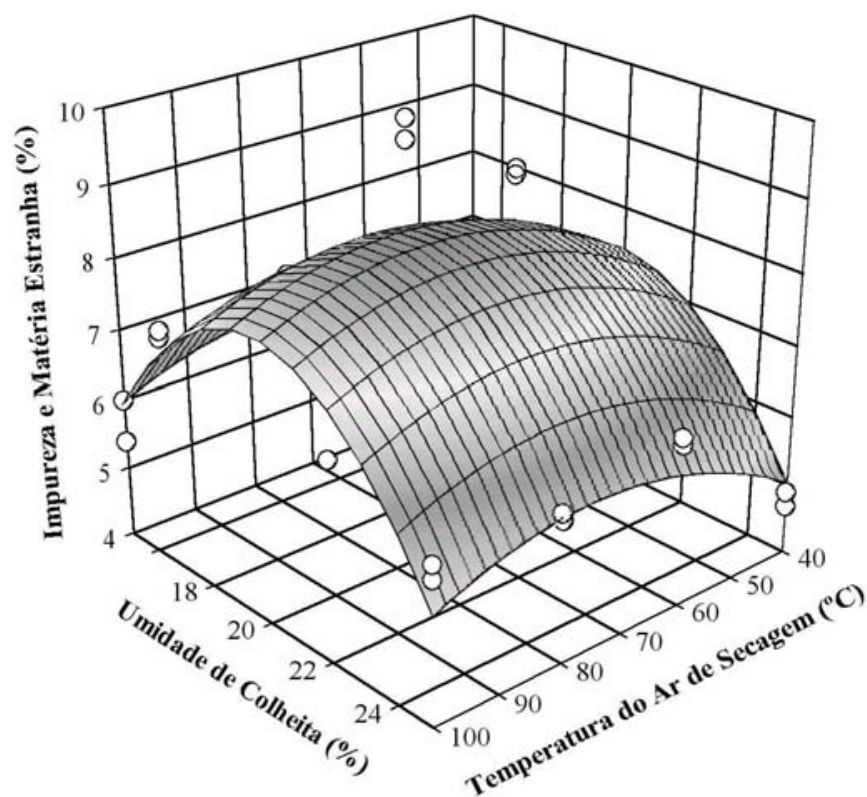

$\mathrm{IME}=-29,51656+0,12536 \mathrm{X}+3,37089 \mathrm{Y}-0,00084 \mathrm{X}^{2}-0,08542 \mathrm{Y}^{2}$ $\left(\mathrm{R}^{2}=0,55\right.$; prob. $\left.<0,01 ; \mathrm{f}=8,10 ; \mathrm{GL}_{\text {res }}=27\right)$

Figura 1. Teor de impureza e matéria estranha (IME) em função do teor de umidade de colheita (Y) e da temperatura do ar de secagem $(\mathrm{X})$ 
de umidade apresentou maior teor de impureza e matéria estranha que o colhido com $15,5 \%$.

\section{Massa específica aparente}

$\mathrm{Na}$ Figura 2 tem-se o efeito da umidade de colheita e da temperatura do ar de secagem sobre a massa específica aparente. Os maiores valores de massa específica aparente foram obtidos para grãos colhidos com 15 e 16,5\% de umidade; independentemente da temperatura do ar de secagem, os menores valores foram obtidos para os grãos colhidos com 22 e $25 \%$ de umidade. Observa-se que para todos os teores de umidade de colheita, os valores da massa específica aparente tendem a diminuir a medida em que se aumenta a temperatura do ar de secagem; tal comportamento fica mais evidenciado na umidade de 22 e $25 \%$. Uma explicação para este fato é que a massa específica é reduzida com o aumento dos danos ocorridos nos grãos, pelo manuseio mecanizado e por outras situações de estresse (Pomeranz et al., 1986) como, também, pelo aumento da temperatura do ar de secagem (Hall, 1972; Brown et al., 1979) resultando, assim, em uma quantidade menor de grãos por metro cúbico.

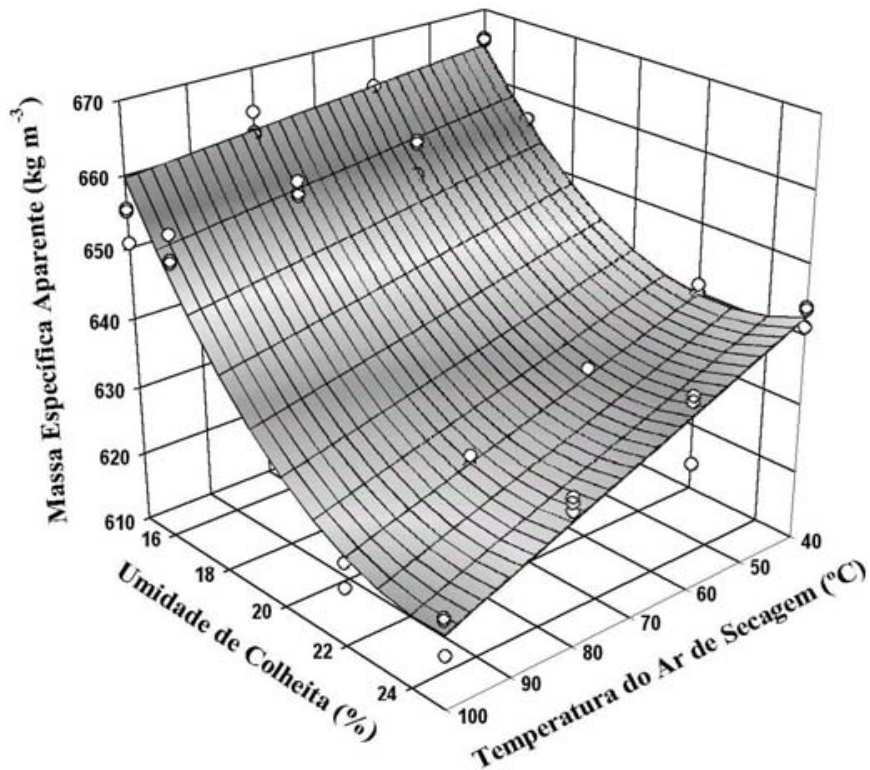

$\mathrm{ME}=879,32963+0,26571 \mathrm{X}-21,4232 \mathrm{Y}+0,50453 \mathrm{Y}^{2}-0,02558 \mathrm{XY}$

$$
\left(\mathrm{R}^{2}=0,97 ; \text { prob. }<0,01 ; \mathrm{f}=204,83 ; \mathrm{GL}_{\text {res }}=27\right)
$$

Figura 2. Massa específica (ME) dos grãos de milho em função do teor de umidade de colheita $(\mathrm{Y})$ e da temperatura do ar de secagem $(\mathrm{X})$

\section{Índice de danos}

O efeito do teor de umidade de colheita e da temperatura do ar de secagem sobre o índice de danos pode ser visualizado na Figura 3. Observa-se que, para grãos colhidos com teor de umidade entre 16,5 e $22 \%$, o índice de danos foi maior que nas demais umidades de colheita, independentemente da temperatura do ar de secagem utilizada. Para todos os teores de umidade de colheita nota-se ligeiro aumento do índice de danos, sempre que se aumenta a temperatura do ar de secagem. Os menores valores de índice de danos foram obtidos para o teor de umidade de colheita de $15 \%$, independentemente da temperatura do ar de secagem. Estes resultados estão de acordo com os obtidos por Silva (1997), que encontrou maior índice de danos quando os grãos foram colhidos com $20,5 \%$ b.u. de umidade em relação a $15,5 \%$ b.u.

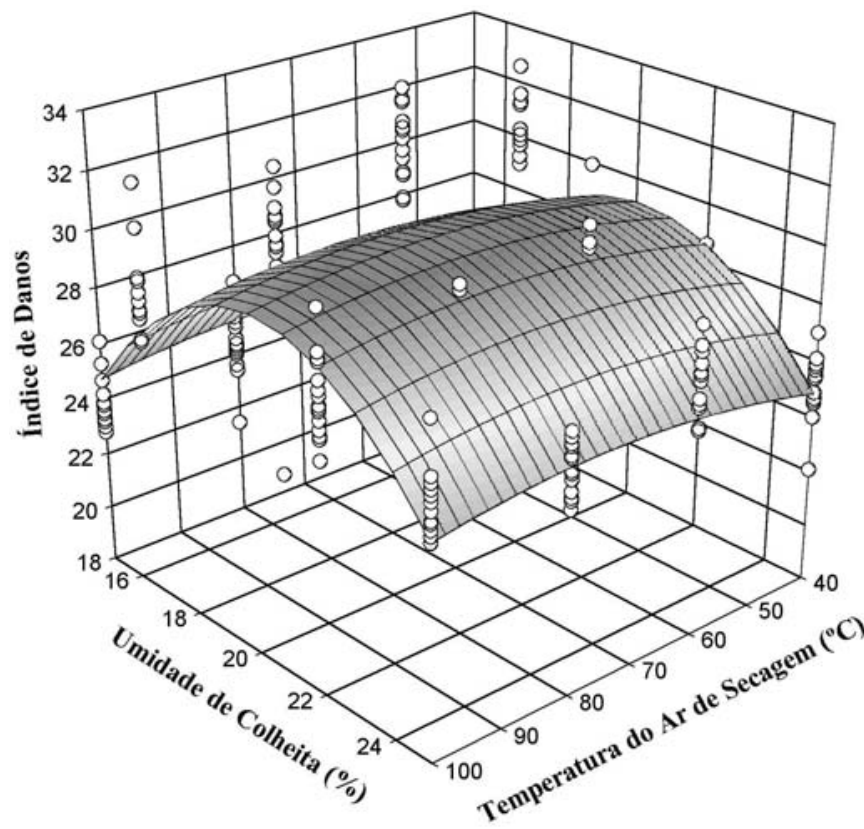

$$
\mathrm{ID}=-50,57328+0,13099 \mathrm{X}+7,52548 \mathrm{Y}-0,00087 \mathrm{X}^{2}-0,18653 \mathrm{Y}^{2}
$$$$
\left(\mathrm{R}^{2}=0,39 ; \text { prob. }<0,01 ; \mathrm{f}=37,36 ; \mathrm{Gl}_{\text {res }}=235\right)
$$

Figura 3. Índice de danos (ID) em grãos de milho, em função do teor de umidade de colheita $(\mathrm{Y})$ e da temperatura do ar de secagem $(\mathrm{X})$

\section{Índice de trincas}

$\mathrm{Na}$ Figura 4 tem-se o efeito do teor de umidade de colheita e da temperatura do ar de secagem sobre o índice de trincas. Verifica-se que o índice de trincas dos grãos aumenta com a elevação da temperatura do ar de secagem e do teor de umidade de colheita dos grãos. Os menores índices de trincas ocorreram, portanto, quando os grãos foram colhidos com teores de umidade de 15 e $16,5 \%$, e secados com a temperatura do ar de secagem de $40{ }^{\circ} \mathrm{C}$. Os resultados obtidos seguem a mesma tendência dos encontrados por Weller et al. (1990) segundo os quais o número de trincas é maior com o aumento do teor de umidade de colheita e da temperatura do ar de secagem. Pode-se associar esses resultados, ainda, com os relatos dos seguintes autores: segundo Naplava et al. (1995) o fator mais importante associado à formação de trincas é a temperatura do ar de secagem e, conforme Thompson \& Foster (1963), Gunasekaran et al. (1985) e Kirleis \& Stroshine (1990) as trincas internas estão geralmente associadas à rápida secagem do milho em altas temperaturas, formando um gradiente de umidade dentro do grão.

\section{Susceptibilidade à quebra dos grãos}

Verifica-se que a susceptibilidade à quebra dos grãos é maior com o aumento do teor de umidade de colheita e da temperatura do ar de secagem (Figura 5). Ressalta-se, no entanto, que este aumento é mais acentuado para os grãos colhidos com teores de umidade entre 22 e $25 \%$ e secados nas temperaturas de 80 e $100{ }^{\circ} \mathrm{C}$. Pode-se inferir, portanto, que os melhores resultados foram obtidos quando se realizaram as colheitas de 15 e 16,5\% 


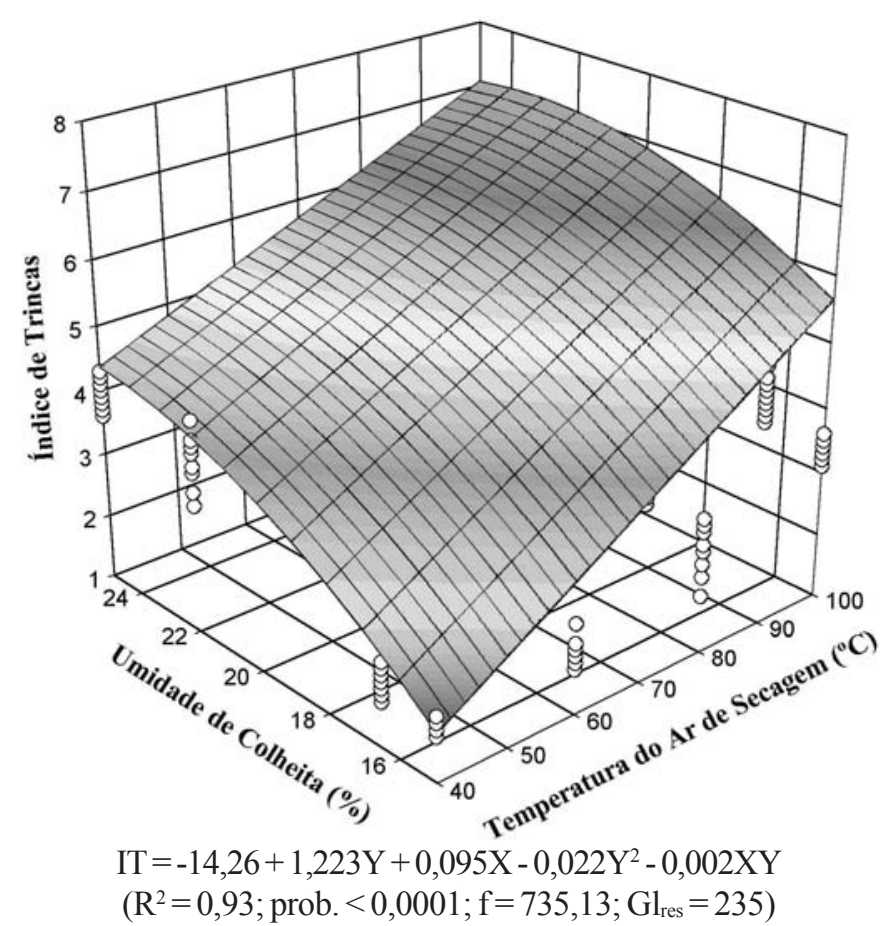

Figura 4. Índice de trincas (IT) nos grãos de milho, em função do teor de umidade de colheita (Y) e da temperatura do ar de secagem $(X)$

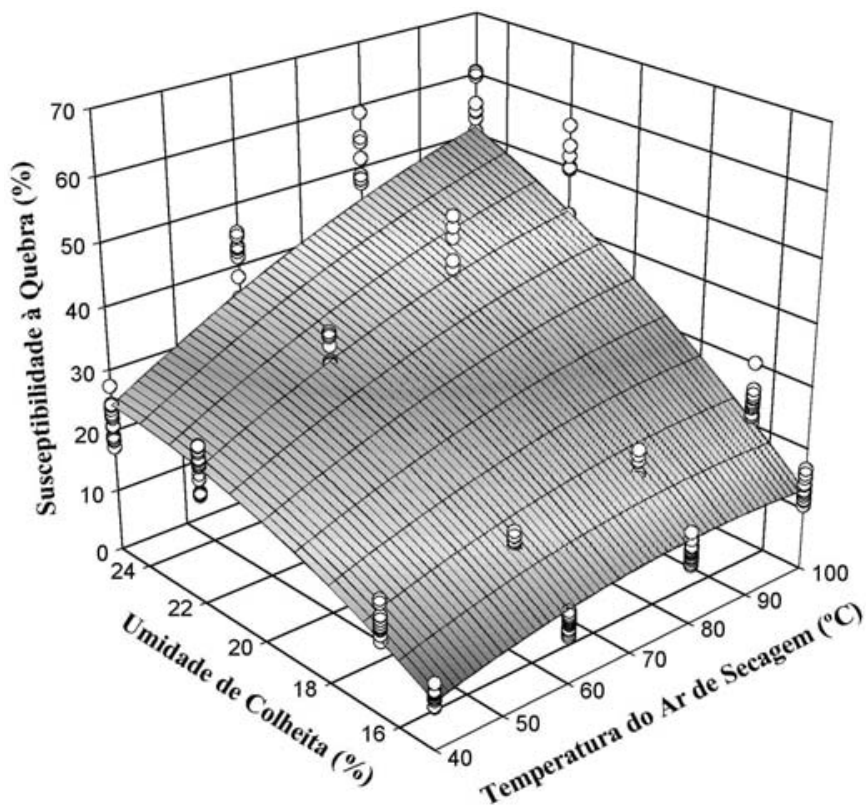

$\mathrm{SQ}=-65,43832+5,8856 \mathrm{Y}-0,00309 \mathrm{X}^{2}-0,1405 \mathrm{Y}^{2}+0,03526 \mathrm{XY}$

$\left(\mathrm{R}^{2}=0,89 ;\right.$ prob. $\left.<0,0001 ; \mathrm{f}=485,43 ; \mathrm{GL}_{\text {res }}=235\right)$

Figura 5. Susceptibilidade à quebra dos grãos (SQ) em função do teor de umidade de colheita $(\mathrm{Y})$ e da temperatura do ar de secagem $(\mathrm{X})$

de umidade, resultados que se assemelham aos obtidos por Thompson \& Foster (1963), Kline (1972) e Silva (1997) ao verificarem que, quanto maior o teor de umidade na época da colheita, maior também foi a susceptibilidade à quebra dos grãos de milho.

Uma outra explicação para o aumento da susceptibilidade dos grãos à quebra é a influência direta da temperatura na intensidade das trincas e estas, por sua vez, segundo
Gunasekaran \& Muthukumarappan (1993) e Paulsen \& Hill (1985) sobre a susceptibilidade à quebra.

$\mathrm{O}$ efeito da temperatura do ar de secagem e do período de armazenamento sobre a susceptibilidade à quebra dos grãos, é representado na Figura 6, podendo-se inferir que ocorreu ligeiro aumento da susceptibilidade dos grãos à quebra, ao longo do período de armazenamento, em cada temperatura do ar de secagem.

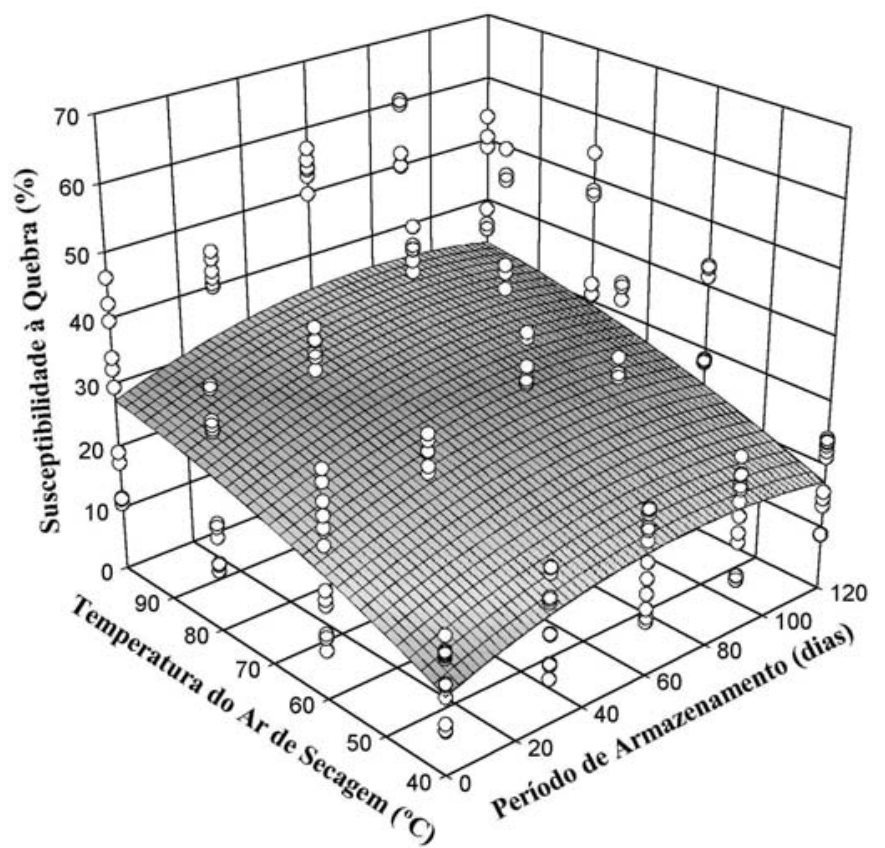

$$
\mathrm{SQ}=-8,00933+0,58733 \mathrm{Y}+0,19545 \mathrm{X}-0,00235 \mathrm{Y}^{2}-0,00125 \mathrm{X}^{2}
$$$$
\left(\mathrm{R}^{2}=0,21 ; \text { prob. }<0,01 ; \mathrm{f}=15,95 ; \mathrm{GL}_{\text {res }}=235\right)
$$

Figura 6. Susceptibilidade à quebra dos grãos (SQ) em função da temperatura do ar de secagem (Y) e do período de armazenamento $(\mathrm{X})$

\section{CONCLUSÕES}

As análises dos resultados permitiram as seguintes conclusões:

1. As menores médias de teor de impureza e matéria estranha foram obtidas com a colheita de $15 \%$ b.u. e as maiores com 16,5 e $22 \%$, independentemente da temperatura do ar de secagem utilizada.

2. A massa específica aparente diminui a medida em que se aumenta a umidade de colheita dos grãos e a temperatura do ar de secagem.

3. Os menores valores de índice de danos foram obtidos para o teor de umidade de colheita de $15 \%$ e os maiores para os grãos colhidos com 16,5 e $22 \%$, independentemente da temperatura do ar de secagem.

4. O índice de trincas dos grãos de milho tornou-se maior com o aumento da temperatura do ar de secagem e da umidade de colheita dos grãos.

5. Grãos colhidos com 15 e 16,5\% de umidade e secados com temperatura do ar de $40{ }^{\circ} \mathrm{C}$, foram os que apresentaram os menores valores de susceptibilidade à quebra.

6. Os melhores resultados foram obtidos quando se realizou a colheita dos grãos com os teores de umidade de 15 e 16,5\% e 
quando os grãos foram secados as temperaturas do ar de secagem de 40 e $60^{\circ} \mathrm{C}$.

\section{AGRADECIMENTOS}

À Financiadora de Estudos e Projetos - FINEP, pelo apoio financeiro.

\section{LITERATURA CITADA}

Araújo, R.F. Efeito da colheita mecanizada nas perdas quantitativas e qualitativas de sementes de milho (Zea mays, L.). Viçosa: UFV, 1995. 103p. Tese Doutorado

Bakker-Arkema, F.W. Grain quality and management of grain quality standards. In: International symposium of grain conservation. 1993, Canela. Anais... Porto Alegre: Plus Comunicações, 1994. p.3-11.

Brasil. Ministério da Agricultura. Regras para análises de sementes. Brasília: 1992.365p.

Brasil. Ministério da Agricultura e do Abastecimento. Indicadores da agropecuária. Brasília. 2000. 50p.

Brooker, D.B.; Bakker-Arkema, F.W.; Hall, C.W. Drying and storage of grains and oilseeds. New York: van Nostrand Reinhold, 1992.450p.

Brown, R.B.; Fulford, G.N.; Daynard, T.B.; Meiering, A.G.; Otten, L. Effect of drying method on grain corn quality. Cereal Chemistry, St. Paul, Minnesota, v.56, n.6, p.529-532, 1979.

Chowdhury, M.H.; Buchele, W.F. Development of a numerical damage index for critical evaluation of mechanical damage of corn. Transactions of the ASAE, St. Joseph, v.19, n.3, p.428-432, 1976.

Fornasieri Filho, D. A cultura do milho. Jaboticabal: FUNEP, 1992.273p.

Franceschini, A.S. Danos mecânicos, qualidade fisiológica e desenvolvimento populacional de Tribolium spp. em milho híbrido BR 201, submetido a diferentes condições de secagem. Viçosa: UFV, 1997. 72p. Dissertação Mestrado

Gunasekaran, S.; Deshpande, S.S.; Paulsen, M.R.; Shove, G.C. Size characterization of stress cracks in corn kernels. Transactions of the ASAE, St. Joseph, v.28, n.5, p.1668-1672, 1985.

Gunasekaran, S., Muthukumarappan, K. Breakage susceptibility of corn of different stress-cracks categories. Transactions of the ASAE, St. Joseph, v.36, n.5, p.1445-1446, 1993.

Hall, G.E. Test weight changes of shelled corn during drying. Transactions of the ASAE, St. Joseph, v.15, n.2, p.320-323, 1972.
Henderson, S.M.; Perry, R.L.; Young, J.H. Principles of process engineering. 4.ed. St. Joseph, Mic.: ASAE, 1997.353p.

Kirleis, A.W.; Stroshine, R.L. Effects of hardness and drying air temperature on breakage susceptibility and dry-milling characteristics of yellow dent corn. Cereal Chemistry, St. Paul, Minnesota, v.67, n. 6, p. 523-528, 1990.

Kline, G.E. Mechanical damage to corn during harvest and drying. In: Grain damage symposium, 1972, Columbus. St. Joseph: ASAE, 1972. p.79-82.

Melendez, J.; Grenovero, S.; Capellacci, H. Antecipated maize harvest in Entre Rios province. In: Congresso argentino de ingeniería rural, 2, 1992, Villa Maria, Argentina. Resumo... Villa Maria, AR: Universidad Tecnologica Nacional; Unidad Academica Villa Maria, 1992.p.101.

Minas Gerais. Secretaria de Estado da Agricultura, Pecuária e Abastecimento. Cenário futuro para a cadeia produtiva de milho em Minas Gerais. Belo Horizonte, 1995. v.11, 34p.

Montross, J.E.; Montross, M.D.; Bakker-Arkema, F.W. Grain storage. In: Bakker-Arkema, F. W. (ed.). CIGR handbook of agricultural engineering. St. Joseph: ASAE, 1999. v.4, p.46-59.

Naplava, V.; Weingartmann, H.; Boxberger, J. Quality research of seed maize during drying and conditioning. Drying of seed corn and stress cracks. Bodenkultur, Vienna, Austria, v.46, n.1, p.51-62, 1995.

Paulsen, M.R.; Hill, L.D. Corn quality factors affecting dry milling performance. Journal Agricultural Engineering Research, Academic Press London, v.31, n.2, p.255-263, 1985.

Peplinski, A.J.; Paulis, J.W.; Bietz, J.A.; Pratt, R.C. Drying of high-moisture corn: Changes in properties and physical quality. Cereal Chemistry, St. Paul, Minnesota, v.71, n.2, p.129-133, 1994.

Pomeranz, Y.; Hall, G.E.; Czuchajowska, Z.; Lai, F.S. Test weight, hardness and breakage susceptibility of yellow dent corn hybrids. Cereal Chemistry, St. Paul, Minnesota, v.63, n.4, p.349-351, 1986.

Roskens, B. Annual meeting - industry comments. Grain Quality Newsletter, Wisconsin, USA, v.16, n.2, p.3-4, 1995.

Silva, A.A.L. Desenvolvimento de um índice para avaliação de danos mecânicos em grãos de milho. Engenharia na Agricultura, Viçosa, v.5, n.3, p.244-253, 1997.

Thompson, R.A.; Foster, G.H. Stress cracks and breakage in artificially dried corn. Washington, D.C.: USDA, 1963. 18p. Marketing Research Report, No. 631

Weller, C.L.; Paulsen, M.R.; Steinberg, M.P. Stress cracking and breakage susceptibility as affected by moisture content at harvest for four yellow dent corn hybrids. Transactions of the ASAE, St. Joseph, v.33, n.3, p.863-869, 1990. 